\title{
Residential water information management
}

\author{
H.E. Jacobs \\ Department of Civil Engineering \\ Stellenbosch University, South Africa \\ hejacobs@sun.ac.za
}

Key words: Water demand management (WDM), water information management (WIM), residential water use, end-use model

Received: 19 September 2008

\section{Contents}

1. Introduction

2. Residential water use

2.1 Urban water-use profile

2.2 Contribution by individual end-uses to indoor demand

2.3 Contribution by outdoor use to total demand

2.4 Water-saving potential

3. Managing water or managing information?

3.1 Water information management and data flow paths

3.2 Type 2 data challenge

4. End-use modelling of residential water use

4.1 Review of end-use model

4.2 Mathematical model description

5. Model parameters

5.1 Comprehensive list of parameters

5.2 Parameter simplification by means of simple logic

6. Internet as channel to obtain model input parameters

6.1 Concept

6.2 Pilot project in the City of Cape Town, South Africa

6.3 Application of Microsoft ASP.Net application and database design

6.4 Lessons learned

7. Future research needs

7.1 Increased participation and parameter prioritisation

7.2 Personal on-site water resources and sewer flow

7.3 Water-related energy consumption in South Africa

8. Summary

9. Acknowledgements

10. $\underline{\text { References }}$

\section{Introduction}

Since ancient times water has been compared to life. Research has since shown that $60 \%$ to $70 \%$ of an adult's body weight is water (Burke 1995), suggesting that there is an important link between water and human life. The effective application of fresh water as a scarce resource is essential for the human race to survive in increasing numbers on planet Earth. This is especially true for geographical regions where the water demand is increasing, due to the growing population or an improved living standard, and is reaching the limit of the available water resources. Southern Africa is such a region. Despite the significance of water as resource and the problems facing South Africa with regard to service delivery, only one article listing 'water' in the title (Rademeyer and Snyman 2004) has appeared in the South African Journal of Information Management since its inception in June 1999. It is hoped that this article will spark interest and lead to further publications pertaining to water in this journal. 
In this article, the focus is on potable water, intended for drinking and other residential uses, as opposed to raw water that is required for irrigation and agricultural purposes. Potable water is supplied to consumers by a water service provider, generally the local authority (LA) or municipality, via a piped water distribution system (WDS). In some countries the service provider is known as a 'water utility', but the term is uncommon in the South African civil engineering fraternity. It this article the use of LA is preferred.

The LA has the responsibility of effectively managing water demand by consumers in its area of jurisdiction. Each LA is required by law to regularly compile a water services development plan (WSDP). The WSDP could be viewed as a reporting standard that addresses various aspects of water use and information pertaining to it. One of the sections of the WSDP addresses the issue of water demand management (WDM), which is termed demand-side management (DSM) in the USA. WDM is defined by Hunt, McDevitt and Hunt (1998) as follows: 'To better manage how and when water is used.'

To better manage how and when water is used, it is essential to gain detailed knowledge of the water used on a particular property. This type of detailed focus is known as end-use modelling or micro-modelling of water use. In this article, two types of data pertaining to water use and reports on recent advances with regard to Web-based data input to end-use models are defined. It has been noted in previous studies that information, which in turn is derived from data, is needed in order for a water authority to function properly (Johnson 2002). The focus in this article is on the flow of information from the end-user (water consumer) to the LA (water manager or analyst), because this aspect is particularly challenging due to the data hungry nature of end-use models.

\section{Residential water use}

\subsection{Urban water-use profile}

Residential water use is one component of the complete urban water-use profile. Other components include, for example, industrial, business or commercial, institutional and municipal water use as well as water loss (Hall and Watson 2000). Flack (1982) reports residential water use as the largest single category of urban water use in the USA, at times exceeding $75 \%$ of total urban demand. In an analysis of water use in the City of Cape Town (CCT), South Africa, residential water consumers were found to contribute almost $90 \%$ towards the total number of water users and about $55 \%$ to the total water-use volume (Jacobs, Fair, Geustyn, Daniels and Du Plessis 2007). A focus on residential customers therefore includes the most notable part of urban water use.

Water is fed to a property via a metered water connection and pressurized water pipes, as depicted schematically in Figure 1 ( $\mathrm{M}$ indicates the water meter and the dotted line the property boundary). On the property the water is used by the consumer to meet various desired needs, some of which are for indoor demands and others to meet outdoor demands. Each of the individual water needs could be viewed as an enduse of water. This investigation exclusively addresses residential water use at the resolution of individual enduses.

Figure 1 Schematic presentation of a residential property and water meter (M) 


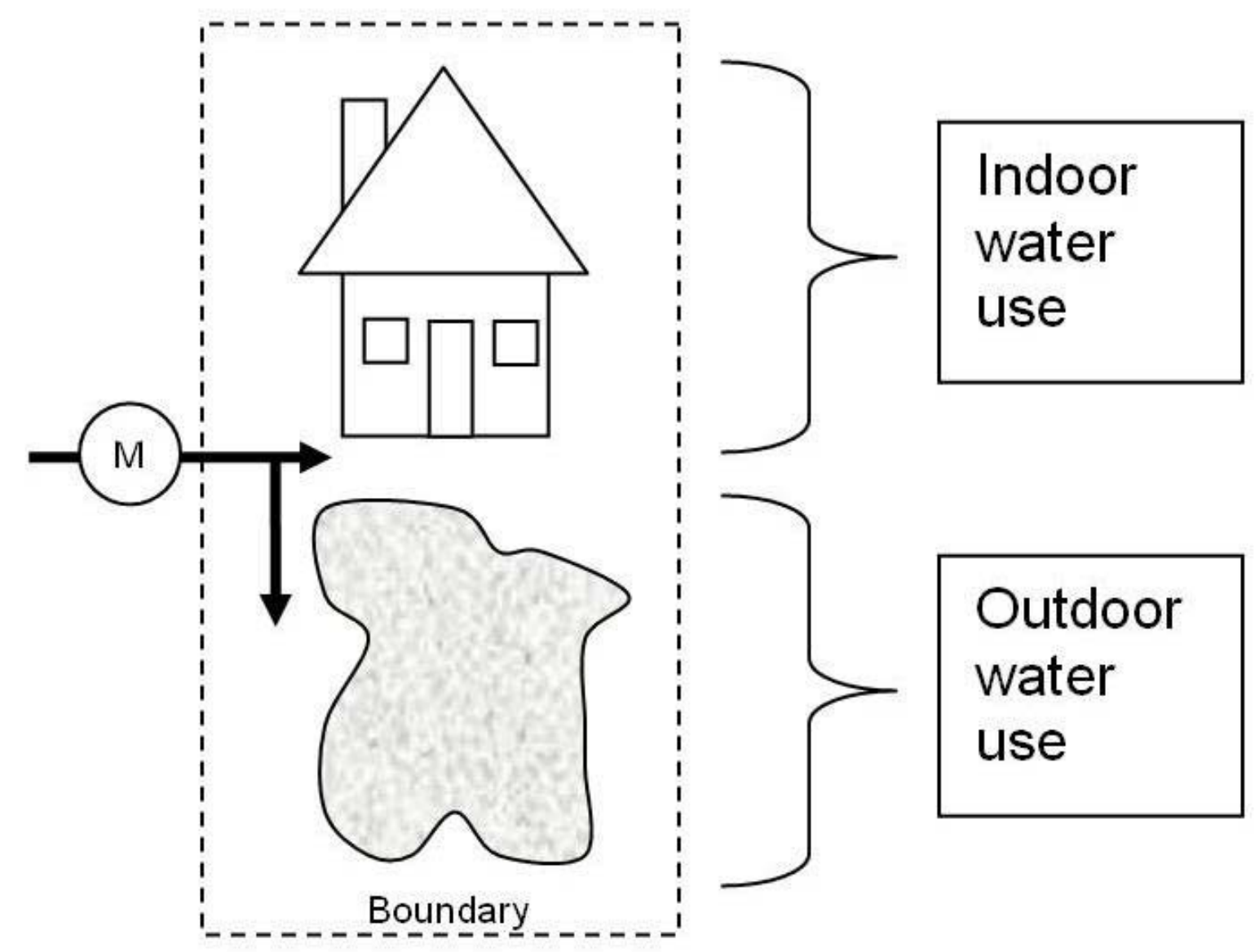

\subsection{Contribution by individual end-uses to indoor demand}

Literature is in broad agreement that the bath, shower, toilet and washing machine combined contribute about $80 \%$ to the total indoor water use in a typical suburban home. In a comprehensive review of 20 international and 12 local studies (Jacobs and Haarhoff 2007), it was noted that the reported combined contribution of these four end-uses was relatively constant with an average contribution of $78 \%$. In 28 of the 32 studies reviewed (i.e. $88 \%$ ) the contribution by these four end-uses combined was found to be in the range $70 \%$ to $90 \%$, despite great variability in dwelling types and study locations (e.g. the UK, USA, Netherlands and South Africa).

\subsection{Contribution of outdoor use to total demand}

Garden water demand contributes most to water demand at residential properties, that is if a garden is present and is irrigated. The share of water used for garden irrigation varies considerably from one study to another - it is clear from literature that garden water demand is hard to predict. DeOreo, Heaney and Mayer (1996) note that dwellings, even in one neighbourhood, may have significant variations in garden demand. In that study, water demand for garden irrigation is reported to contribute $78 \%$ on average to the total summer water demand. This is confirmed by results presented by Veck and Bill (2000) for the perceived water use by customers in Alberton, South Africa. The perceived portion of water used for garden irrigation for specific dwellings varies between $0 \%$ and $70 \%$ of the total. The study even reports significant variations between dwellings in the same neighbourhood. Garlipp (1979) also assessed the perceived portion of water use ascribed to garden irrigation in South Africa and reported it to be $73 \%$. In contrast to the high values reported elsewhere, Edwards and Martin (1995) found that outside taps contributed only $3 \%$ to the total demand in their study in the UK.

\subsection{Water-saving potential}

The end-uses identified as being significant in their contribution to water demand have the potential of contributing most to water savings - the garden, toilet, bath, shower, washing machine and leaks. For this reason, many water restriction campaigns target outdoor use. It is essential that a LA understands the nature of water use by consumers at a higher resolution (i.e. per individual end-use) to improve its WDM initiatives and subsequently improve service delivery to all consumers. 


\section{Managing water or managing information?}

\subsection{Water information management and data flow paths}

Effective management relies on effective measurement and accurate information transfer (Johnson 2008). South African residential water use is metered for the purpose of billing consumers. The water meter reading is required for billing purposes by the LA's financial department and is typically read on a monthly basis in South Africa. The information is transferred via manual user input from meter readers' files to financial billing systems. The corresponding water meter reading and reading date for all water meters in the WDS are stored in the financial billing system (automatic meter reading systems are available, but are not common locally; discussion of the topic falls beyond the scope of this text). The sensitive nature of the information billing systems typically allows for limited access by financial staff only. However, information regarding the wateruse volume is also needed by the LA's technical staff, or engineering consultants, to effectively manage the water use. In this article, information originating from the water meter data and subsequently extracted from the financial billing system is termed Type 1 information. Type 1 information describes the monthly water use per water meter - in residential areas each property typically has only one water meter, as depicted in Figure 1.

In addition to Type 1 information, knowledge regarding each end-use on a property might be needed by demand modelling consultants to estimate water use and potential savings. This information describing enduses on a property is discussed in more detail in this article and is termed Type 2 information.

The question arises as to what actually needs to be managed - water or information? The answer is, 'both'. It is tacit knowledge that the information pertaining to the water use of a customer (e.g. water meter readings, billing information) is fundamental to the water use being managed. It has been reported that information could be viewed as a prerequisite for WDM (Gumbo, Juizo and Van der Zaag 2003:1). Taking after the definition of WDM presented earlier (Hunt et al. 1998), water information management (WIM), as it relates to residential water use, is defined in this article as follows: 'To better manage the information pertaining to how and when water is used.' WIM is crucial in view of LAs' WDM initiatives. Subsequent to WIM, water use could be managed via WDM campaigns to encourage conservative use at end-use level. In other words, effective WDM is based on effective WIM.

WIM is connected to hydro-informatics by definition. Informatics is defined in the Oxford Dictionary as 'the science of processing data for storage and retrieval' (with the preposition hydro meaning 'relating to water'). The combined term hydroinformatics, although not listed in the Oxford Dictionary per se, is defined online (Wikipedia 2008) as 'a branch of informatics which concentrates on the application of information and communications technologies in addressing the increasingly serious problems of the equitable and efficient use of water for many different purposes.' LAs are responsible for effective processing, storing and retrieval of water-use information pertaining to their customers, thus LAs are responsible for the implementation of WIM measures.

For example, in periods of drought or water scarcity, the LA might need to impose water restrictions, such as in the case of CCT during the water restrictions of 2004 to 2005 (Jacobs et al. 2007). Such serious decisions need to be based on accurate knowledge, which in turn should be based on hydroinformatics. With reference to Figure 2, the two types of information that need to be managed are:

- Type 1 - flow of information from the water meter to the analyst (left to right). This is depicted by blue arrows and represents the actual water-use records, based on consumer meter readings (M) flowing first to the financial billing system (FBS) and then via the demand modelling software (Swift) to the engineers (ENG). This is commonly termed the monthly consumption, is measured in $\mathrm{kl} / \mathrm{month}$, and is reflected on a consumer's water bill. Recent reports regarding the management of Type 1 information (Fair and Compion 2008) have shown that the management has evolved to a sophisticated level, allowing for the meter readings to be extracted from billing systems, cleaned and analysed with great success. Monthly water consumption records for almost 2 million water users, obtained via this method, have even been used to compile a National Water Consumption Archive for South Africa (Van Zyl and Geustyn 2007). Further advances include, for example, practical Web-based management of Type 1 data (Sinske and Jacobs 2008; Van den Berg, Fair and Sinske 2008).

- Type 2 - flow of information from the consumer to the analyst (right to left). This is depicted by the green arrow and involves the input parameter values required for modelling the anticipated water demand at end-use level.

Figure 2 Schematic flow of water-use information 


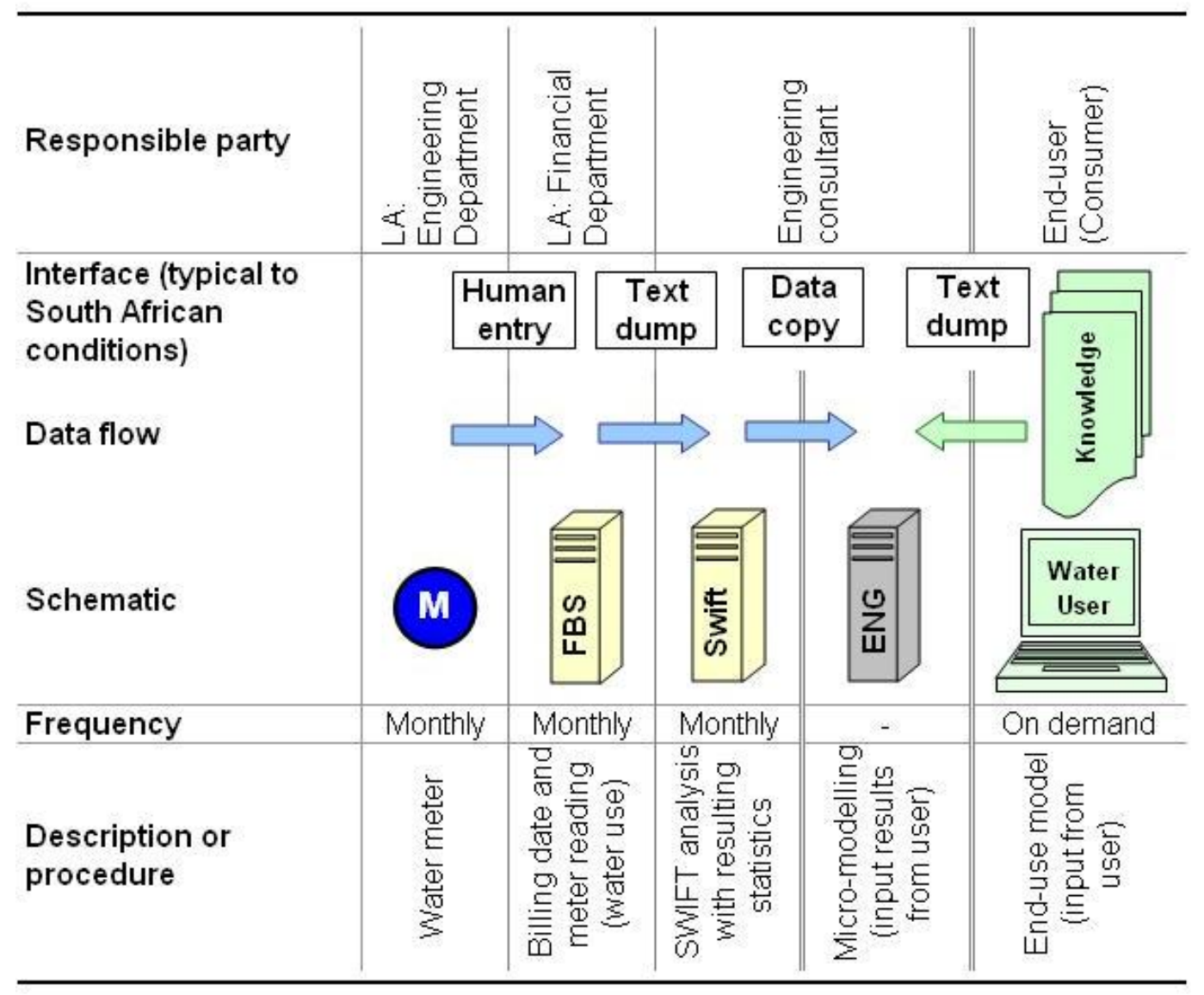

\subsection{Type 2 data challenge}

Type 2 data are required to populate end-use models. Those who venture into this quagmire of data are left with the arduous task of populating end-use models with many parameters prior to modelling water demand at end-use level. For this reason, water demand estimation guidelines in South Africa remain empirical (Jacobs, Geustyn, Loubser and Van Der Merwe2004; Van Zyl, Ilemobade and Van Zyl 2008) and are not based on enduses of demand.

Type 2 information could, for example, be gained from the consumer via survey questionnaires. Alternatively, it could be acquired from existing knowledge based on literature reviews and research findings (Jacobs 2007; Jacobs and Haarhoff 2004b). In this article, the recent trend of Web-based data input to end-use models is addressed.

\section{End-use modelling of residential water use}

End-use modelling of water use has numerous advantages, but one of the main pitfalls is the data-hungry nature of such models. Prior to modelling, knowledge needs to be gained about numerous detailed parameters describing water use in a home. One approach to gain these parameter values is to physically intrude the plumbing in a home and measure the volume and frequency of each individual water-use event for each enduse in the home. No reports of such extensive work are available locally, although international researchers have applied this and other relatively expensive data logging methods successfully (DeOreo, Dietemann, Skeel, Mayer, Lewis and Smith 2001:58; DeOreo et al. 1996:79; Edwards and Martin 1995:477).

Practical application of end-use modelling in South Africa has previously been investigated, with knowledge regarding water use at a resolution of micro-components gained by means of desktop studies (Jacobs 2007:549; Jacobs and Haarhoff 2004b:315) or by contingent valuation (Jacobs 2007:551; Veck and Bill 2000). In limited cases the Internet was evaluated as a means to gain parameter values (Sinske, Jacobs and Geustyn 2006:1-10; Sinske and Jacobs 2008). These studies share a common concern in that a relatively large number of input parameter values are required to describe the residential water use at this resolution.

\subsection{Review of end-use model}


An end-use model called the Residential End-Use Model (REUM) was first developed at the University of Johannesburg (formerly RAU) to analyse end-uses of water at residential properties (Jacobs and Haarhoff 2002). The model concept is shown schematically in Figure 3. The concept was extended and scrutinized to a point where the final model included the following end-uses: bath, bathroom basin, dishwasher, kitchen sink, leaks, miscellaneous indoor, shower, toilet, washing machine, miscellaneous outdoor, a pool and three different types of garden vegetation (e.g. grass and two types of garden bed vegetation).

The model fully describes five components of the water demand for, and wastewater flow from, all end-uses of water at a property by estimating the monthly water flow (split into indoor and outdoor use), hot-water use, wastewater flow and concentration of soluble substances in the wastewater stream. Only the former components pertaining to water use are applicable in this case.

Figure 3 End-use concept

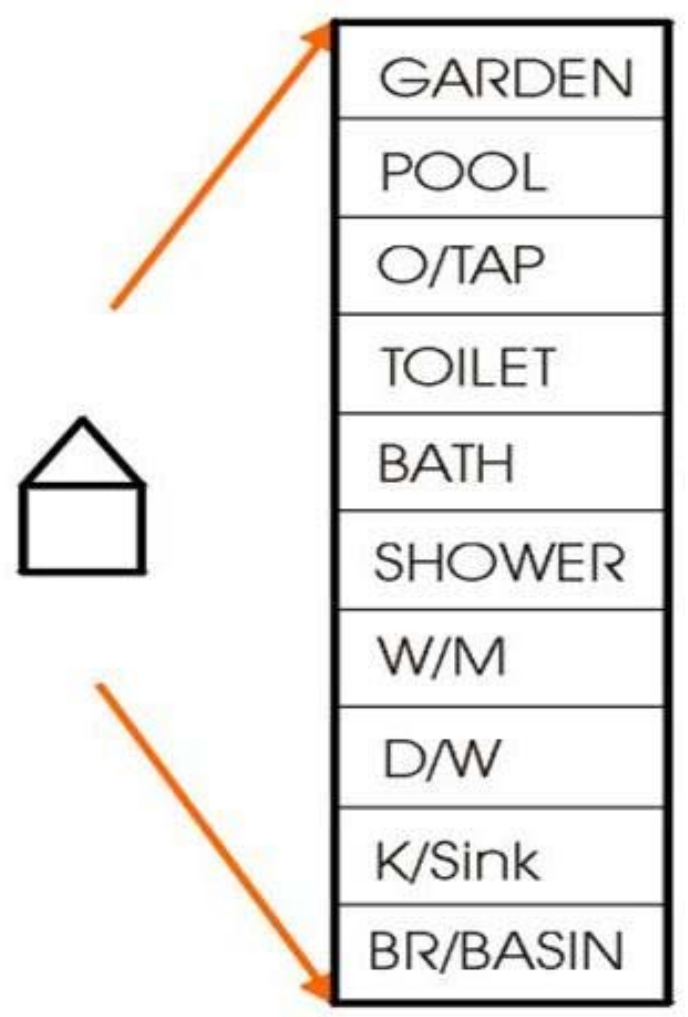

The structure of REUM is depicted by monthly iteration. After selecting parameter values for a particular month, the model calculates results for each end-use and each of the five components in the model for the active month. The annual average daily water demand (AADD) is often used in South Africa as the basis for WDS design and analysis (CSIR 2003:Chapter 9; Jacobs et al. 2004:4) and is obtained with the end-use model by repeating the process for all 12 months, then taking the daily average.

\subsection{Mathematical model description}

Mathematical description of the model structure (Jacobs and Haarhoff 2004a) presents a convenient way forward for computer programming around the model's rigid structure. The eventual model maintains the five model components (the indoor use, outdoor use, hot-water use, wastewater flow and concentration of soluble substances in the wastewater stream). Although an understanding of the mathematical model structure is not crucial to this article, reference to the mathematical description is considered valuable in view of further reading.

\section{Model parameters}

\subsection{Comprehensive list of parameters}

In REUM, the comprehensive data input is stored as a spreadsheet in MS Excel. Its structure replicates a 
database, enabling the input of electronic data from other sources, such as completed survey questionnaires, databases and text dumps ready for end-use analysis. Returned survey responses need to be pre-processed and can then be used to populate the model parameters. In South Africa this method is common for various types of research due to its relatively inexpensive nature, with costs determined mainly by the printing, distribution and gathering of questionnaires and responses.

The data requirement of a locally developed end-use model is discussed by Jacobs and Haarhoff (2004a:297). To completely model one month, 111 parameters are needed, increasing to 1322 parameters to extend the modelling over a full year. It is apparent that simplification was required in view of practical application.

\subsection{Parameter simplification by means of simple logic}

Previous simplifications to the end-use model structure by Jacobs and Haarhoff (2004a:297) led to the number of parameters being drastically reduced to 79 by making simplifying assumptions. These 79 parameters remained after stripping all possible redundancy from the model in terms of its relative impact. However, populating even 79 parameters (for one property) is a daunting task. Some of these parameters are critical, while others might not be.

The choice of parameters was, however, somewhat subjective at the time and led to the formulation of 30 questions, testing about 40 parameter values - the rest had to be populated by default parameter values based on desk-top information. This crude reduction in input parameter values had to be accepted for the interim and was used in the first pilot project in Cape Town, until a better method was devised (as described shortly).

\section{Internet as channel to obtain model-input parameters}

\subsection{Concept}

The idea of implementing the Internet to manage water information was recognized in about 2005, when a Web-based viewer was used in Vernon, Canada (Vandenberg, Kinch nd Jacobs 2005) prior to the concept evolving into a Web-based tool for irrigation water management (www.okim.ca) with the logical extension to include residential demand management. Even prior to this the largest South African water service provider, Rand Water (2002), noted the need to make water-related information available via open-ended structures, including querying via the Internet. Despite identifying the Internet as a valuable medium for conveying waterrelated information, these studies did not focus on end-uses of demand. Two reports of Web-based data input for modelling water use locally followed suite (Sinske et al 2006:2; Sparks, Van Zyl and Carr 2006:1). Both these studies were limited to capturing data via the Internet - no feedback was included to provide the user with modelled results. Only recently have advances been made with practical application of end-use modelling via commercial products on the Internet (www.aquasoft.ca) and also with regard to application of such products in local research and pilot projects (Sinske and Jacobs 2008).

Use of the Internet to capture the input-data is an obvious improvement to the process and is inexpensive after the initial set-up. The concept has developed overseas to a point where commercial software products are on offer to conduct end-use based demand forecasting as well as Web-based applications pertaining to WDS and water demand. In South Africa, however, the use of the Internet for this purpose is still limited to research projects.

\subsection{Pilot project in the City of Cape Town, South Africa}

The method of capturing input-data via the Internet was recently tested in a pilot study in CCT to obtain parameter values for end-use modelling (Sinske et al. 2006:1-10; Sparks et al. 2006:1-3). In the work by Sinske et al., 200 questionnaires were distributed by hand and another 43 via electronic means. Obtaining data in this format via electronic input from users enabled the project team to merely 'cut and paste' the parameter set (text file) received into the MS Excel end-use model for analysis. The database structure consisted of two parts. The first part contained sensitive information about the user, while the second part contained the data representing the response from the 'water-use' questions presented to the user. Responses were either numerical (real or integer values) or logical (Yes/No).

Despite the relatively poor e-response, both studies cited above confirmed that input parameters for end-use modelling could be obtained directly via the Internet locally. The one study also noted the potential of extending the process to a fully fledged tool for Web-based end-use modelling in South Africa, but to date successful application remains limited, mainly due to the large number of parameters required, limited Internet access and data privacy concerns. 


\subsection{Application of Microsoft ASP.Net application and database design}

A Microsoft ASP.Net Web-based application with SQL back-end database was designed for implementation in the pilot project by GLS Engineering Software (Pty) Ltd. (www.gls.co.za). This Web-based application was hosted on a Microsoft Internet Information Server (IIS) at a secure third party computer centre. The database was hosted at the time on Microsoft SQL Server 2000 (Sinske et al. 2006: 3).

Home owners and staff of CCT could access the electronic questionnaire via a link on the main Web site of the CCT. Alternatively, home users with Internet access could directly access the questionnaire on the host site. The application was available for about three months - the duration of the pilot project.

\subsection{Lessons learned}

A significant advantage of the Web-based application was the direct availability of data - from the start of the process. In other words, it was never necessary to manually enter any parameter values, as was the case when inputs were received via hard copy questionnaires returned by fax or completed during door to door visits.

Despite the Internet being considered useful for data capture, the tool was practically useless from the viewpoint of the private home owner (i.e. survey respondent), because no feedback could be provided regarding the modelled result. Extension was required to not only obtain end-use model input parameters, but to model the water use and present the results - not to an analyst in MS Excel, but directly to the home owner via the WWW during an inter-active session.

Media coverage was provided on selected radio stations and in local newspapers during the pilot study period, but only 43 completed responses were received via the Web tool (of which 11 originated from within the project team). Comments by survey respondents and the relatively low number of responses received pointed to additional work - further simplification of the model input was required as it was simply too complex and time consuming in view of the average home owner to address the 30 questions posed. In the case of the pilot project, participants in the survey had to complete their response for both the pre-restriction period and the period during water restrictions, resulting in almost 60 individual responses submitted via the Web tool by each home owner voluntarily taking part in the study.

Security concerns by home owners, requested to enter personal information via the Internet, was noted as a limitation by some users. This aspect is currently addressed in further work to ensure users' privacy (Sinske and Jacobs 2008). In this regard, valuable research has been published on the creation and use of passwords (Wessels and Steenkamp 2007).

\section{Future research needs}

\subsection{Increased participation and parameter prioritisation}

The limited scale pilot study previously conducted in CCT showed that users were not eager to use the Internet for submitting parameter values for end-use modelling their own water use during the particular study period. One likely explanation for this may be that the process was relatively complicated with too many questions, leading to both a complex and time-consuming session.

Simplification of the end-use model input structure by means of parameter prioritisation is an effective means to reduce the input requirement for end-use modelling (Jacobs and Haarhoff 2007). A subsequently simplified questionnaire could be employed to make end-use models more amenable to practical application. Additional methods could also be sought to further improve user participation. In addition, incentives could be used to encourage more users to use the Web-based tool. Incentives could, for example, include a discount on the municipal water bill for those users who regularly make use of the tool.

\subsection{Personal on-site water resources and sewer flow}

Once implemented the tool could be extended to include personal on-site water resources, such as rainwater use, reuse of grey water and also groundwater use via boreholes or well points. Apart from the alternative sources, which were excluded in this study to simplify the process, future extension could include use of the model to evaluate sewer flow from the property. 
The Web-based end-use modelling tool could be integrated into future work on water-related energy consumption in South African households. The tool could become a channel to gain knowledge on hot-water use at home and could be used in conjunction with the energy management initiatives of South Africa's energy supplier, Eskom. Hot-water use is a major contributor to energy consumption in residential homes and reduction of hot water use would lead directly to reduced energy demand at home. In addition, hot water used in homes is generally discarded to the wastewater system via the sewer. Reduced hot-water use would thus lead to reduced sewer flows and, in turn, to reduced energy costs associated with transport and treatment of the wastewater.

Application of the tool with regard to hot water would empower home owners to better understand their own hot-water use and subsequent energy use and potential savings. In this regard it is a valuable education and training tool at grass roots level.

\section{Summary}

The hitherto undefined term 'water information management' (WIM) as it relates to residential water use is defined in this article as follows: 'To better manage the information pertaining to how and when water is used at home.' Effective WDM is based on effective WIM. This article underlines the importance of managing information, obtained from data, to manage water use.

A review of residential water use, with a specific focus on end-uses of demand and information pertaining to it, is presented. Two types of data flow pertaining to water use at residential properties are identified. Type 1 information describes the monthly water use at a residential property recorded in the LA's financial billing system, while Type 2 information describes end-uses on a particular property. End-use models of water demand require Type 2 data as input, are renowned to be data hungry and are often arduous to populate.

A method for populating the model parameters with a Web-based tool is also addressed. Success at gaining parameter values for end-use modelling via Web-based tools has been somewhat limited to date, but it is hoped that future improvements in simplifying the input requirement would lead to practical application. A former pilot study in CCT tested the capturing of input data, but did not extend beyond this somewhat limited functionality. Work is currently progressing on the international front to a point of practical application. It is hoped that application locally would soon follow suit.

In addition to LAs and their demand management consultants gaining access to valuable end-use information with a Web-based tool, application of such a tool at household level would serve as a means for user education - home owners would learn more about their own water use, identify the most significant end-uses at home and be empowered to save water more effectively by focusing water saving efforts at 'the right' end-uses. In addition, the tool would provide valuable data inputs for research into end-use modelling of water use.

\section{Acknowledgements}

The author would like to acknowledge assistance provided by Dr Alexander Sinske (GLS Software) and Dr Leon Geustyn (GLS Consulting) as well as financial support provided by the Stellenbosch University's Engineering faculty (Sub-Committee B) for continued research into end-use modelling of residential demand.

\section{References}

Burke, E.R. 1995. Serious cycling. University of Colorado, Human Kinetics.

CSIR. 2003. Guidelines for human settlement planning and design. A report compiled by the Council for Scientific and Industrial Research (CSIR) Building and Construction Technology under the patronage of the Department of Housing (South Africa).

DeOreo, W.B., Dietemann, A., Skeel, T., Mayer, P.W., Lewis, D.M. and Smith, J. 2001. Retrofit realities. Journal of the American Waste Water Association 93(3):58-72.

DeOreo, W.B., Heaney, J.P. and Mayer, P.W. 1996. Flow trace analysis to assess water use. Journal of the 
Edwards, K. and Martin, L. 1995. A methodology for surveying domestic water consumption. Water and Environmental Management 9:477-488.

Fair, K.A. and Compion, J.K. 2008. The water distribution system master planning process in South Africa with a focus on metered demand-, water loss monitoring-, calibration- and financial analysis. Proceedings of the 10th Annual Water Distribution Systems Analysis Conference WDSA2008, Van Zyl, J.E., Ilemobade, A.A. and Jacobs, H.E. (eds.), August 17-20, 2008, Kruger National Park, South Africa: 47-56.

Flack, J.E. 1982. Urban water conservation: Increasing efficiency-in-use residential water demand. A report for the engineering foundation and endorsed by the water resources planning and management division of ASCE, ASCE, New York 1982:1-111.

Garlipp, D.K.C.O. 1979. Water consumption patterns in urban areas. (M.Sc. thesis). Pretoria: University of Pretoria, Water Research Group, Department of Chemical Engineering. [Unpublished].

Gumbo, B., Juizo, D. and Van der Zaag, P. 2003. Information is a prerequisite for water demand management: experiences from four cities in Southern Africa. Elsevier Ltd. Physics and Chemistry of the earth, 28:827-837. [Online]. Available WWW: http://www.sciencedirect.com (Accessed 10 September 2008).

Hall, E. and Watson, M. 2000. Urban water consumption. IWA, Managing water and waste in the new millennium, Midrand, Johannesburg, South Africa, 23-26 May 2000:1-9.

Hunt, J.B., McDevitt, W. and Hunt, G. 1998. Water efficiency manual for commercial, industrial and institutional facilities. A joint publication of the Division of Pollution Prevention and Environmental Assistance and Division of Water Resources of the North Carolina Department of Environment and Natural Resources, and the Land-of-Sky Regional Council - WRATT Program, August 1998.

Jacobs, H.E. 2007. The first reported correlation between end-use estimates of residential water demand and measured use in South Africa. Water SA 33(4): 549-558.

Jacobs, H.E., Fair, K., Geustyn, L.C., Daniels, J. and Du Plessis, J.A. 2007. Analysis of water savings: A case study during the 2004-2005 water restrictions in Cape Town. Journal of the South African Institution of Civil Engineers 49(3):16-26.

Jacobs, H.E., Geustyn, L.C., Loubser, B.F., Van Der Merwe, B. 2004. Estimating residential water demand in Southern Africa. Journal of the South African Institution of Civil Engineers 46(4):2-13.

Jacobs, H.E. and Haarhoff, J. 2007. Prioritisation of parameters influencing residential water use and wastewater flow. Journal of Water Supply: Research and Technology - AQUA 56(8):495-514.

Jacobs, H.E. and Haarhoff, J. 2004a. Structure and data requirements of an end-use model or residential water demand and return flow. Water SA 30(3):293-304.

Jacobs, H.E. and Haarhoff, J. 2004b. Application of a residential end-use model for estimating cold and hot water demand, wastewater flow and salinity. Water SA 30(3):305-316.

Jacobs, H.E. and Haarhoff, J. 2002. End-use modelling as a means to predict the effects of water demand management. Proceedings of the Water Institute of South Africa Biennial Conference, Durban, South Africa, May 2002. [Online]. Available WWW: http://www.ewisa.co.za/literature/ (Accessed 10 September 2008).

Johnson, E.H. 2008. Management of non-revenue and revenue water data. EA Books, Crows Nest, Australia (www.engineersmedia.com.au/bookshop).

Johnson, E.H. 2002. Integrated water asset management system (IWAMS), Paper 99, IWA Conference, Melbourne, Australia, April 2002.

Rademeyer, P. and Snyman, M.M.M. 2004. Competitiveness of the water utility consulting industry on the Internet in South Africa. South African Journal of Information Management 6(3):1-7.

Rand Water. 2002. Investigation into MIS which can be adopted in the Gauteng province, final report, Rand Water, Johannesburg. 
Sinske, A.N. and Jacobs, H.E. 2008. Modelling residential water use with a Web-based tool. In: Proceedings of the 10th WWW conference (ZA-WWW), Cape Town, 3-5 September 2008.

Sinske, A.N., Jacobs, H.E. and Geustyn, L.C. 2006. Internet-based water demand management. Proceedings of the Water Institute of South Africa Biennial Conference, Durban, South Africa, 22-25 May 2006. [Online]. Available WWW: http://www.ewisa.co.za/literature/ (Accessed 10 September 2008).

Sparks, A., Van Zyl, B. and Carr, N. 2006. Home water audit - a Web-based tool promoting water awareness and allowing the collection of data on water use patterns. Proceedings of the Water Institute of South Africa Biennial Conference, Durban, South Africa, 22-25 May 2006. [Online]. Available WWW:

http://www.ewisa.co.za/literature/ (Accessed 10 September 2008).

Van den Berg, T.N., Fair, K.A. and Sinske, A.N. 2008. What are the benefits of universal water metering? Lessons learned at the district of West-Vancouver, British Columbia, Canada. Proceedings of the 10th Annual Water Distribution Systems Analysis Conference WDSA2008. Van Zyl, J.E., Ilemobade, A.A. and Jacobs, H.E. (eds.), August 17-20, 2008, Kruger National Park, South Africa:209-220.

Vandenberg, T., Kinch, J. and Jacobs, H.E. 2005. Significant advances in information technology and water supply and demand management at Greater Vernon Services. Canadian

Water Resource Association, Conference, Kelowna, Canada, 21-24 February 2005.

Van Zyl, J.E. and Geustyn, L.C. 2007. Development of a national water consumption archive. South African Water Research Commission Report No. 1605/1/07.

Van Zyl, H.J., Ilemobade, A.A. and Van Zyl, J.E. 2008. An improved area-based guideline for domestic water demand estimation in South Africa. WaterSA 34(3):381-392.

Veck, G.A. and Bill, M.R. 2000. Estimation of the residential price elasticity of demand for water by means of a contingent evaluation approach. Water Research Commission Report Number 790/1/00.

Wessels, P.L. and Steenkamp, L.P. 2007. Assessment of current practices in creating and using passwords as a control mechanism for information access. South African Journal of Information Management 9(2):1-7.

Wikipedia. 2008. [Online]. Available at: http://en.wikipedia.org/wiki/Main_Page. (Accessed 10 September 2008). 
ISSN 1560-683X

Published by InterWord Communications for Department of Information and Knowledge Management, University of Johannesburg 